\title{
A Normal Distribution-Based Methodology for Analysis of Fatal Accidents in Land Hazardous Material Transportation
}

\author{
Cuiping Ren ${ }^{1}{ }^{\mathbb{D}}$, Qunqi $\mathrm{Wu}^{1}{ }^{1}$, Chunguo Zhang ${ }^{2, *}$ and Shengzhong Zhang ${ }^{1}$ \\ 1 School of Economics and Management, Chang'an University, Xi'an 710064, China; \\ believe.323@163.com (C.R.); wqq@chd.edu.cn (Q.W.); szzhang@chd.edu.cn (S.Z.) \\ 2 Key Laboratory of Road Construction Technology and Equipment, MOE, Chang'an University, \\ Xi'an 710064, China \\ * Correspondence: cgzhang@chd.edu.cn
}

Received: 4 June 2018; Accepted: 6 July 2018; Published: 7 July 2018

\begin{abstract}
The deaths of accident occurring in land hazardous material transport (rail and road) is a scale standard for judging accident severity in safety programmes. The $f$ - $N$ curve is a common practice to express the results from past scattered accident data through curve fitting method, which only estimate the overall trend. For this reason, this paper proposed a simple methodology by combination of normal distribution and $f-N$ curve. To verify the method, the following three sets of statistical data were selected and analysed in this study: 1932 accidents in over 95 countries (1931-2004) and 322 accidents in China (2000-2008) available in the literature, and 2046 accidents investigated in China (2013-2017). It was found that the mean value curve is almost identical or even better than the best-fitted curve, while the predicted upper and lower limits with $96 \%$ reliability $( \pm 2 \sigma)$ covering nearly all the statistical data are beyond the scope of common curve fitting. The result explains the inherent relation between accumulated frequency and deaths in different transport mode, in different country and at different period. This study also provides insights on the evolution of accident severity with the development of social economy and the requirement of safety.
\end{abstract}

Keywords: hazardous material transportation; fatal accidents; normal distribution; $f-N$ curve; safety programmes

\section{Introduction}

Hazardous material accidents occurring in land transport often result in fateful consequences to the population and environment due to the characteristics of dangerous goods. Programmes on safety improvement have been conducted in many countries, such as the Hazardous material Cooperative Research Program (HMCRP) in the United States, the 5-year plan for safety production in China, and the zero-accident goal by 2050 in EU. Therefore, it is important to evaluate the effects of accident severity in safety programmes and make suitable plans with the development of social economy and the requirement of safety.

Several studies using statistical data have discussed the accident severity with different methods [1-3]. For example, Ellis et al. [4] analysed the ratio of hazmat-ship accidents to overall-ship accidents, and Zhang et al. [5] used the proportion of death to injury for hazardous chemical accidents. Abdolhamidzadeh et al. [6] presented the average number of fatalities per accident globally. Brüde [7] described a model for successively monitoring the development of fatalities. These studies mostly make a simple overview of death and injury, without deeply analysis on accident severity. Due to incomplete or inaccurate information of accidents (e.g., economic loss and injured degree) [8,9], it is 
statistically impossible to conduct a comprehensive study considering all the consequences of hazmat accidents. In this study, only fatal accidents, which are nearly $100 \%$ precise, were considered [10].

The $f-N$ curve (social risk curve) is commonly used to describe the accident severity, by presenting the relationship between the accumulated probability and the number of deaths [11-14]. Except for marine accidents of hazmat transportation, straight lines are obtained by plotting an $\mathrm{f}-\mathrm{N}$ curve for road, rail and pipeline accidents [15]. The slope of the straight line, obtained by normal curve fitting, is used to evaluate the accident severity as a metric. For example, by comparing the slope of the $f$ - $N$ curve, Hemmatian et al. [16] and Darbra et al. [17] concluded that hazmat accidents involving domino effects have slightly more severe consequences for the affected population than that of hazmat accidents without domino effects.

A new method with a mean value curve based on normal distribution was proposed to be identical or even better than the best-fitted curve [18,19]. Furthermore, predictions with $96 \%$ reliability $( \pm 2 \sigma)$ of the upper and lower bounds covering nearly all the statistical data are beyond the scope of normal curve fitting [18], and this may also be used for the prediction of severity analysis on fatal accidents. On this basis, the aim of this paper is to propose a methodology based on normal distribution and the $f-N$ curve and, therefore, to explore ways to decrease fatal accidents with the related safety policies and programmes.

\section{Methodology}

\subsection{Data Resource}

Hazardous material accidents mostly happened during transportation, especially in land transport; in China, at least $80 \%$ of hazmat transportation accidents occurred on the road [2]. However, the accident statistical data is limited due to underreported accidents-for example, some states only report accidents that result in property damage above a specific threshold dollar amount, while others require the degree of vehicle damage to be above a certain level [20]. In addition, it is well-known that individuals involved in accidents involving no injury or minor injury are far less likely to have their crashes reported to the police. A technical report by the National Traffic Safety Administration [21] estimated that $25 \%$ of minor injury accidents and half of no-injury crashes are unreported-a sharp contrast to fatal crashes, for which the reporting rate is nearly $100 \%$ [10].

Recognizing the limited accident information is an important consideration in selecting an appropriate sample data. Hence, this study selected accidents with at least one death that occurred in land hazardous material transportation, and three sets of data were analysed in this study. One data set is digitized from Oggero conducting a survey of 1932 accidents (including 242 fatal accidents) occurred during the land transport of hazardous material from over 95 countries. Oggero et al. [11] analysed fatalities with an $f-N$ curve which provides a comparative study for testing the normal distribution-based method. The second sample data set is digitized from Yang et al. [12] with 322 accidents occurred during the road hazmat transportation in China from 2000 to 2008. The reliability of graphic digitalization has been checked by comparing with the original result in the literature. It is found that the digitized error is no more than $1 \%$, which is acceptable. In addition, deaths analysis with an $f-N$ curve was also carried out in Yang et al. [12]. The third data set contains 2046 accidents (including 217 accidents caused deaths) happened in road hazardous material transportation in China from 2013 to 2017, and these data are investigated from the Journal of Safety and Environment and Chemical Accidents Information Network. Detailed information was gathered from the newspaper and the Internet.

\subsection{Method}

The $f$ - $N$ curve is a method expressing the results of risk evaluation. It refers to accumulated frequency of $\mathrm{N}$ people or more than $\mathrm{N}$ people affected in accidents. For evaluating the severity of fatal accidents in hazmat transportation, the most commonly used method is to plot $f-N$ curve by 
showing the relation between accumulated frequency and number of deaths. Accidents with at least one fatality were selected and grouped according to the number of deaths. The cumulative probability or frequency is calculated by the following expression:

$$
P_{(x \geq N)}=F_{j}=\frac{\sum_{i=j}^{n} N_{i}}{\sum_{i=1}^{n} N_{i}}
$$

where $N$ is the number of deaths ( $x$-axis), $P_{(x \geq N)}=F_{j}$ is the probability that the number of deaths is equal or more than $N$ ( $y$-axis) in an accident, $n$ is the total number of categories or rankings, and $N_{i}$ is the number of accidents in a given category $i$.

In a $\log -\log$ system, $F_{j}$ is roughly linear to $N_{i}$ for land transport accidents $\left(\lg F_{j}=b \cdot \lg N_{i}\right)$, which is different to the marine transport that has a hump in the $f-N$ curve [15]. To better present this distribution in quantification and visualization, previous studies have obtained the best fitted curve with a slope of $b$ [11-14]. The slope of $b$ refers to relative probability, which means, for example, that the probability of an accident involving 10 or more deaths is $10^{-b}\left(F=10^{b} / 100^{b}=10^{-b}=N^{-b}\right.$, when $N=10$ ) times greater than that of an accident involving 100 or more deaths. However, the value of $b$ is different in various conditions-for example, the slope is -0.81 from Oggero et al. [11] while -0.84 was obtained in Vílchez [14]. Therefore, it is essential to obtain the value of $b$ in precise.

The slope of $b$ is defined by the intersection of two criteria- $F$ and $N$, and is normally distributed by using Equation (2). Therefore, the distribution of $b_{i}$ can be obtained with the corresponding mean value $\mu$ and the standard deviation $\sigma$.

$$
f(x)=\frac{1}{\sigma \sqrt{2 \pi}} e^{-\frac{(x-\mu)^{2}}{2 \sigma^{2}}}
$$

The distribution of $b_{i}$, closest to a normal distribution with the smallest standard deviation is used to determine the relative probability and make a prediction of an $f-N$ curve with the mean $(\mu)$ and deviation $(\sigma)$. With the accumulated probability $(F)$, the number of deaths $\left(N_{i}\right)$, and the corresponding standard deviations $(\sigma)$, the equation of a straight line can be written to include the mean value curve and upper and lower limits with $96 \%$ reliability $( \pm 2 \sigma)$, i.e.,

$$
F=\left\{\begin{array}{c}
(\bar{b}+2 \sigma) \times N_{i} \\
\bar{b} \times N_{i} \\
(\bar{b}-2 \sigma) \times N_{i}
\end{array}\right.
$$

The above equation means that the relative probability can be fully predicted with the mean $\mu$ $(\mu=\bar{b})$ and the standard deviation $\sigma$. The severity of accidents can then be analysed with an accurate mean value curve and upper and lower limits that address the fluctuation of accidents in hazardous material transportation.

To show the usefulness of the methodology, we examine the relation between accumulated frequency and number of deaths in different transport mode, in different country and at different period.

\section{Results}

\subsection{Severity Analysis of Fatalities in Different Transport Mode}

The severity of fatal accidents occurred in different transport mode is different. In this paper, by plotting an $f-N$ curve based on normal distribution, we conducted a comparative study to analyse the severity of fatalities of road and rail transport accidents. There are 31 results $\left(F, N_{i}\right)$ in road and 18 results $\left(F, N_{i}\right)$ in rail both digitized from Oggero et al. [11], listed in Tables 1 and 2, respectively. In the table, NA means $b_{i}$ is not available in a log-log system. 
Table 1. Accumulated frequency of road accidents with $N$ deaths digitized from Oggero et al. [11].

\begin{tabular}{ccccccccc}
\hline $\boldsymbol{N}_{\boldsymbol{i}}$ & $\boldsymbol{F}$ & $\boldsymbol{b}_{\boldsymbol{i}}$ & $\boldsymbol{N}_{\boldsymbol{i}}$ & $\boldsymbol{F}$ & $\boldsymbol{b}_{\boldsymbol{i}}$ & $\boldsymbol{N}_{\boldsymbol{i}}$ & $\boldsymbol{F}$ & $\boldsymbol{b}_{\boldsymbol{i}}$ \\
\hline 1 & 1.000 & $\mathrm{NA}$ & 12 & 0.170 & -0.713 & 40 & 0.060 & -0.763 \\
2 & 0.550 & -0.862 & 13 & 0.160 & -0.714 & 43 & 0.054 & -0.776 \\
3 & 0.420 & -0.790 & 14 & 0.150 & -0.719 & 44 & 0.049 & -0.797 \\
4 & 0.390 & -0.679 & 15 & 0.140 & -0.726 & 50 & 0.042 & -0.810 \\
5 & 0.330 & -0.689 & 16 & 0.130 & -0.736 & 60 & 0.036 & -0.812 \\
6 & 0.310 & -0.654 & 17 & 0.120 & -0.713 & 61 & 0.030 & -0.853 \\
7 & 0.270 & -0.673 & 21 & 0.110 & -0.714 & 62 & 0.023 & -0.914 \\
8 & 0.220 & -0.728 & 22 & 0.090 & -0.719 & 100 & 0.019 & -0.861 \\
9 & 0.210 & -0.710 & 23 & 0.071 & -0.726 & 170 & 0.012 & -0.861 \\
10 & 0.200 & -0.699 & 30 & 0.064 & -0.736 & 200 & 0.006 & -0.966 \\
11 & 0.190 & -0.693 & & & & & \\
\hline \multicolumn{7}{c}{ Normal distribution: $\mu=-0.770, \sigma=0.0768$} \\
\hline
\end{tabular}

Based on the corresponding experimental data in Oggero et al. [11], the slope of $b_{i}$ is normally distributed from Equation (2) with the mean value $\mu=-0.770$ and the standard deviation $\sigma=0.0768$ (in Figure 1a). The $f-N$ curves of the mean value and the predictions of upper and lower limits from Equation (3) were plotted in Figure 1b, together with previous result-a fitted curve (in blue colour). The fitted curve is plotted from the digitized data and is identical to the original result in the literature.
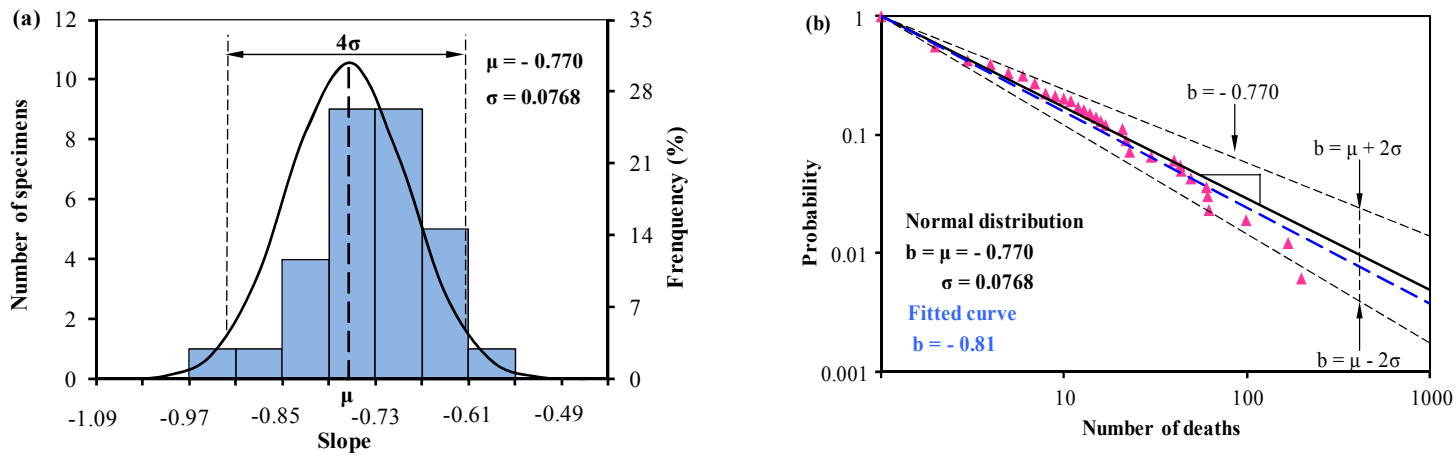

Figure 1. (a) Normal distribution analysis of the slope $b_{i}$ determining the relation between the accumulated frequency and number of deaths, and (b) predictions from Equations (1) and (3) based on the normal distribution analysis of $b_{i}$ in (a) together with the statistical data in road accidents from 1931 to 2004 digitized from Oggero et al. [11].

The mean value curve (the black straight line) in Figure $1 \mathrm{~b}$, based on normal distribution, is slightly different from the fitted curve (the blue dotted line). The mean value curve $(b=-0.77)$ describes these experimental results even better than the best-fitted curve $(b=-0.81)$ [11]. The same result that the normal distribution is identical or better than the curve fitting was published by Zhang et al. [18]. The gradient of the upper dashed line is -0.616 , and the gradient of the lower dashed line is -0.924 . This indicates that the relative frequency of an accident involving 10 or more deaths versus an accident involving 100 or more deaths, ranges from 4.1 to $8.4\left(F=10^{-b}\right)$, and the mean value is 5.9.

Table 2 presents the accumulated frequency $(F)$, the number of deaths $\left(N_{i}\right)$ and the slope of $b_{i}$ for rail transport accidents (NA means $b_{i}$ is not available). The same as road accidents, the slope of $b_{i}$ in rail accidents is normally distributed from Equation (2) with the mean value $\mu=-0.752$ (approximately 0.75 in the literature) and the standard deviation $\sigma=0.062$. Figure 2 shows the distribution of fatalities and the $f-N$ curves with the mean value and the predictions of upper and lower limits from Equation (3), together with a fitted curve from Oggero et al. [11] on a log-log system. 
Table 2. Accumulated frequency of rail accidents with $N$ deaths digitized from Oggero et al. [11].

\begin{tabular}{cccccc}
\hline $\boldsymbol{N}_{\boldsymbol{i}}$ & $\boldsymbol{F}$ & $\boldsymbol{b}_{\boldsymbol{i}}$ & $\boldsymbol{N}_{\boldsymbol{i}}$ & $\boldsymbol{F}$ & $\boldsymbol{b}_{\boldsymbol{i}}$ \\
\hline 1 & 1000 & $\mathrm{NA}$ & 13 & 0.130 & -0.795 \\
2 & 0.650 & -0.621 & 15 & 0.120 & -0.783 \\
3 & 0.430 & -0.768 & 16 & 0.095 & -0.849 \\
5 & 0.320 & -0.708 & 22 & 0.081 & -0.813 \\
6 & 0.290 & -0.691 & 28 & 0.067 & -0.811 \\
7 & 0.270 & -0.673 & 41 & 0.054 & -0.786 \\
8 & 0.220 & -0.728 & 71 & 0.042 & -0.744 \\
9 & 0.190 & -0.756 & 110 & 0.028 & -0.761 \\
11 & 0.140 & -0.820 & 581 & 0.014 & -0.671 \\
\hline \multicolumn{6}{c}{ Normal distribution: $\mu=-0.752, \sigma=0.062$} \\
\hline
\end{tabular}

In Figure 2, the slope of the fitted curve (-0.748) [11] is almost identical to the slope of the mean value curve (0.752). $b_{i}$ ranges from -0.873 to -0.630 using Equation (3). This means, for example, an accident involving 10 or more deaths is 4.3 to $7.5\left(F=10^{-b}\right)$ times greater than an accident involving 100 or more deaths, and the mean value is 5.6.
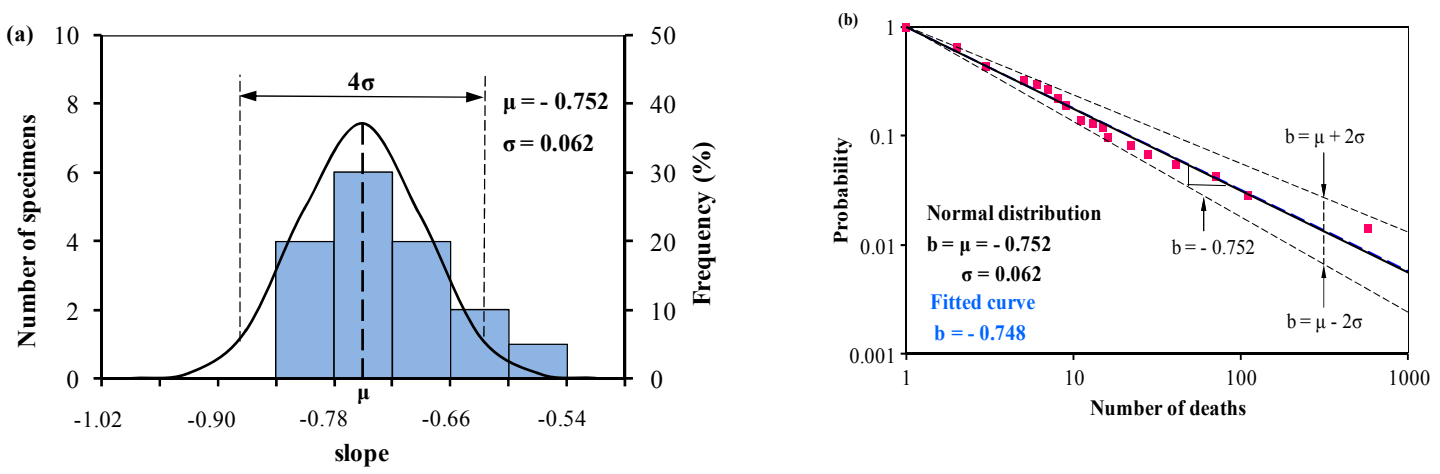

Figure 2. (a) Normal distribution analysis of the slope $b_{i}$ determining the relation between the accumulated frequency and number of deaths, and (b) predictions from Equation (1) and Equation (3) based on the normal distribution analysis of $b_{i}$ in (a) together with the statistical data in rail accidents from 1931 to 2004 available in Oggero et al. [11].

Results show that the slope of $f-N$ curve (the mean value curve) of rail accidents is less than the slope of road accidents, showing fatal accidents occurred in rail transport is more severe than in road transport in general. However, the scope of predictions with upper and lower bounds in road accidents $(-0.924--0.616)$ contains the scope of rail accidents $(-0.873--0.630)$, and this indicates that the severity of fatal accidents occurred in road transport is more severe in the upper bound and is less severe in the lower bound than that of rail transport.

\subsection{Severity Analysis of Fatalities in Different Country}

The severity of fatal accidents is closely pertinent to the development of the country. Oggero et al. [11] analysed the fatalities of accidents by grouping countries into three groups: (1) United States, Canada, Australia, Japan, New Zealand and Norway; (2) the European Union; and (3) the rest of the world. Countries in Group 1 and Group 2 are all well-developed, while countries in Group 3 are almost developing countries. Oggero et al. [11] concluded that the severity of accidents in the first two groups is similar and in group (3) the severity of accidents is clearly higher than in the first two.

To conduct a comparative study on the differences of severities influenced by the level of development in different countries, we use the same sample and groups from Oggero's [11]. In total, 13 data points $\left(F, N_{i}\right)$ of Group 1,11 data points $\left(F, N_{i}\right)$ of Group 2, and 33 data points $\left(F, N_{i}\right)$ of Group 
3 were digitized, and listed in Table 3. All these data contains fatal accidents occurred in both road and rail hazmat transportation in the same period. NA means $b_{i}$ is not available in a $\log -\log$ system in Table 3.

Table 3. Accumulated frequency of land transport accidents with $N$ deaths for the three groups digitized from Oggero et al. [11].

\begin{tabular}{|c|c|c|c|c|c|c|c|c|}
\hline \multicolumn{4}{|c|}{ Group 1: US, Canada, Australia, etc. } & \multicolumn{5}{|c|}{ Group 2: EU } \\
\hline$N_{i}$ & \multicolumn{2}{|l|}{$F$} & $b_{i}$ & \multicolumn{2}{|r|}{$N_{i}$} & \multicolumn{2}{|c|}{$F$} & $b_{i}$ \\
\hline 1 & \multicolumn{2}{|l|}{1.000} & NA & \multicolumn{2}{|r|}{1} & \multicolumn{2}{|c|}{1.000} & NA \\
\hline 2 & \multicolumn{2}{|l|}{0.520} & -0.943 & \multicolumn{2}{|r|}{2} & \multicolumn{2}{|c|}{0.370} & -1.434 \\
\hline 3 & \multicolumn{2}{|l|}{0.330} & -1.009 & \multicolumn{2}{|r|}{3} & \multicolumn{2}{|c|}{0.280} & -1.159 \\
\hline 4 & \multicolumn{2}{|l|}{0.250} & -1.000 & \multicolumn{2}{|r|}{4} & \multicolumn{2}{|c|}{0.210} & -1.126 \\
\hline 5 & \multicolumn{2}{|l|}{0.210} & -0.970 & \multicolumn{2}{|r|}{6} & \multicolumn{2}{|c|}{0.170} & -0.989 \\
\hline 6 & \multicolumn{2}{|l|}{0.200} & -0.898 & \multicolumn{2}{|r|}{7} & \multicolumn{2}{|c|}{0.130} & -1.048 \\
\hline 7 & 0.170 & & -0.911 & & 8 & & & -1.061 \\
\hline 8 & 0.085 & & -1.185 & & 11 & & & -1.033 \\
\hline 9 & 0.070 & & -1.210 & & 13 & & & -1.072 \\
\hline 10 & 0.054 & & -1.268 & & 16 & & & -1.135 \\
\hline 11 & 0.040 & & -1.342 & & 200 & & & -0.729 \\
\hline 15 & 0.030 & & -1.295 & & & & & \\
\hline 21 & 0.017 & & -1.338 & & & & & \\
\hline & nal distribu & ution: $\mu=$ & $=-1.114, o$ & .175 & Normal & tributi & $u=-1$. & $\sigma=0.174$ \\
\hline & & & Grou & the $\operatorname{Re}$ & st of the Wor & & & \\
\hline$N_{i}$ & $F$ & $b_{i}$ & $N_{i}$ & $F$ & $b_{i}$ & $N_{i}$ & $F$ & $b_{i}$ \\
\hline 1 & 1.000 & NA & 12 & 0.430 & -0.340 & 43 & 0.160 & -0.487 \\
\hline 2 & 0.880 & -0.184 & 13 & 0.410 & -0.348 & 44 & 0.140 & -0.520 \\
\hline 3 & 0.740 & -0.274 & 14 & 0.410 & -0.338 & 50 & 0.130 & -0.522 \\
\hline 4 & 0.650 & -0.311 & 15 & 0.370 & -0.367 & 60 & 0.110 & -0.539 \\
\hline 5 & 0.640 & -0.277 & 16 & 0.310 & -0.422 & 61 & 0.100 & -0.560 \\
\hline 6 & 0.610 & -0.276 & 21 & 0.310 & -0.385 & 62 & 0.088 & -0.589 \\
\hline 7 & 0.580 & -0.280 & 22 & 0.270 & -0.424 & 71 & 0.075 & -0.608 \\
\hline 8 & 0.550 & -0.287 & 28 & 0.210 & -0.468 & 100 & 0.057 & -0.622 \\
\hline 9 & 0.540 & -0.280 & 30 & 0.210 & -0.459 & 110 & 0.043 & -0.669 \\
\hline 10 & 0.490 & -0.310 & 40 & 0.200 & -0.436 & 170 & 0.030 & -0.683 \\
\hline 11 & 0.480 & -0.306 & 41 & 0.180 & -0.462 & 581 & 0.015 & -0.660 \\
\hline & & & Normal d & tion: $p$ & $u=-0.428$ & 138 & & \\
\hline
\end{tabular}

According to Equation (2), we draw the same conclusion that the slope of $b_{i}$ is normally distributed and equal to the original literature for all the three groups. Based on a normal distribution, we obtain the mean value curve and the predictions with upper and lower lines, together with the fitted curve commonly used, and they are listed in Figures 3-5.

In Figures 3 and 4 , the mean value of Group $1(b=-1.114)$ is very close to the mean value in Group $2(b=-1.079)$, and this two groups include most developed countries. This indicates that the severity of fatalities occurred in developed countries is similar. While the predicted slopes with the upper and lower bounds describe the gap between Group 1 and Group 2 by using Equation (3). In Group 1, the relative probability for the deaths ranges from 5.8 to 29.1, and in Group 2, this value ranges from 5.4 to 26.7. This indicates in the countries (i.e., United States, Canada, Australia, et al.) of Group 1, fatalities caused in the accident of hazardous material transportation may appear to higher volatility than in EU of Group 2.

In Group 3, the slope of the mean value curve is -0.428 , and is much higher than the first two groups. The slopes of predictions with upper and lower bounds ranges from -0.152 to -0.704 (Figure $5 b$ ), and this means an accident involving 10 or more deaths is 1.4 to $5.1\left(F=10^{-b}\right)$ times greater than an accident involving 100 or more deaths. Comparing to the first two groups, the severity of 
fatalities in Group 3 is the highest, and this result is in good agreement with the study published by Oggero et al. [11].
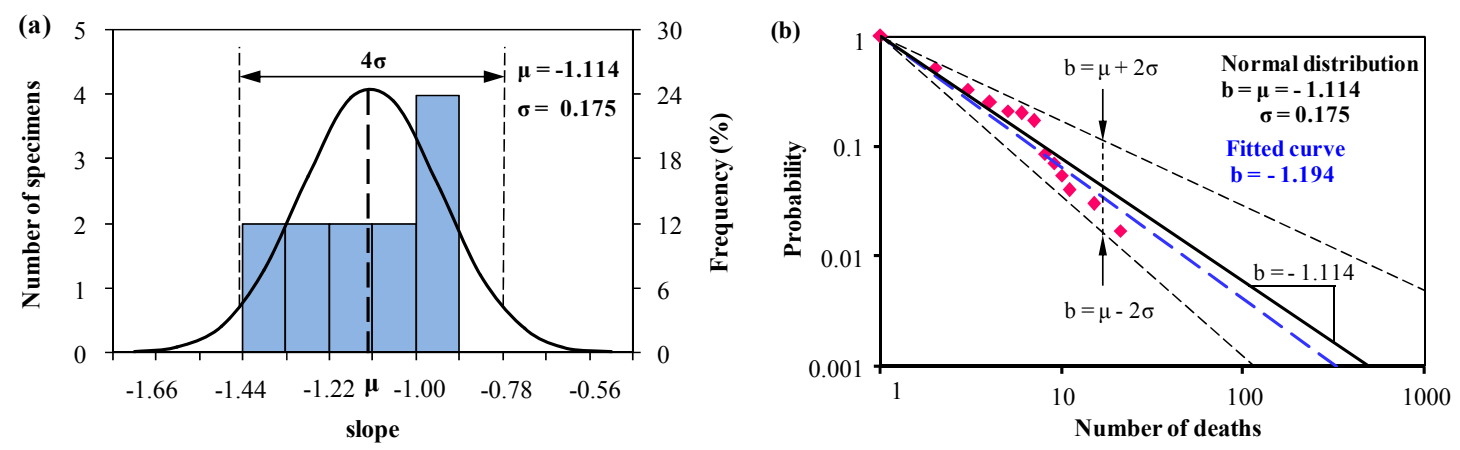

Figure 3. (a) Normal distribution analysis of the slope $b_{i}$, and (b) predictions from Equation (1) and Equation (3) based on the normal distribution analysis of $b_{i}$ in (a) for Group 1 together with the statistical data (1931-2004) available in Oggero et al. [11].
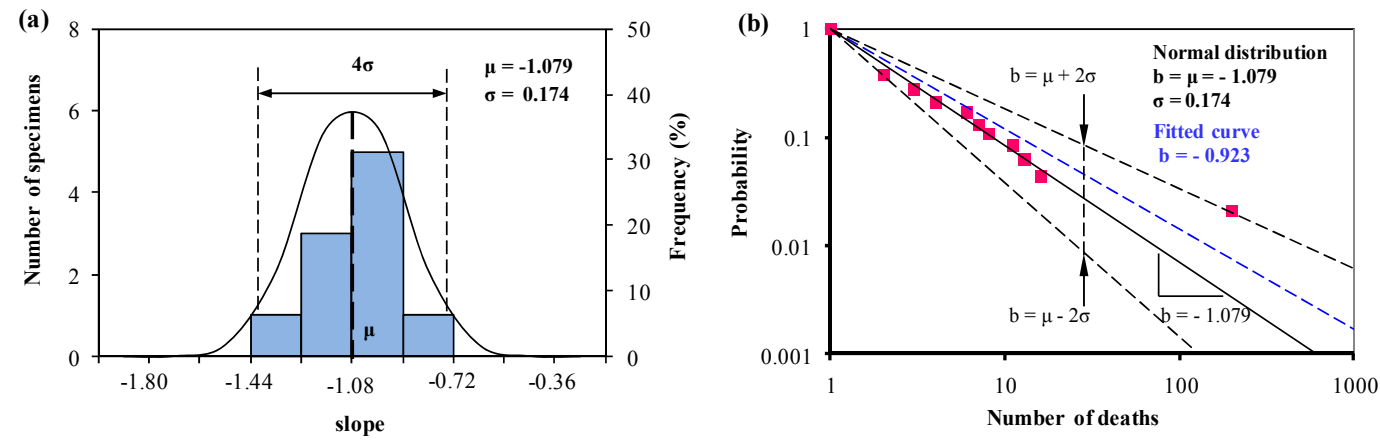

Figure 4. (a) Normal distribution analysis of the slope $b_{i}$, and (b) predictions from Equation (1) and Equation (3) based on the normal distribution analysis of $b_{i}$ in (a) for Group 2 together with the statistical data (1931-2004) available in Oggero et al. [11].
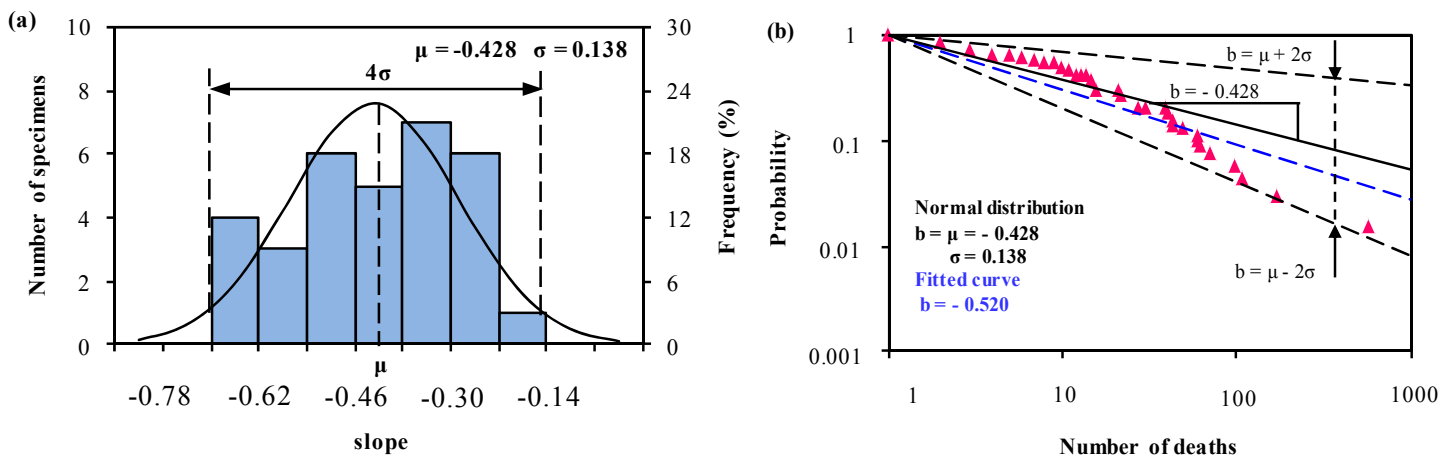

Figure 5. (a) Normal distribution analysis of the slope $b_{i}$, and (b) predictions from Equation (1) and Equation (3) based on the normal distribution analysis of $b_{i}$ in (a) for Group 3 together with the statistical data (1931-2004) available in Oggero et al. [11].

\subsection{Severity Analysis of Fatalities at Different Period}

To provide an updated survey and conduct a comparative study on the severity of fatal accidents occurred in the road transportation of hazardous material, this study selected 322 accidents (2000-2008) with 8 data points $\left(F, N_{i}\right)$ digitized from Yang et al. [12] and investigated 2046 accidents including 
217 fatal accidents (2013-2017) with 11 data points $\left(F, N_{i}\right)$ in China. All the data points are listed in Table 4 and NA is not available.

Table 4. Accumulated frequency of hazardous material accidents occurred in road transportation with $N$ deaths from Yang et al. [12] and investigation in different periods of China.

\begin{tabular}{cccccc}
\hline \multicolumn{2}{c}{ 2000-2008 (Yang et al. [12]) } & \multicolumn{3}{c}{ 2013-2017 (Investigated Data) } \\
\hline $\boldsymbol{N}_{\boldsymbol{i}}$ & $\boldsymbol{F}$ & $\boldsymbol{b}_{\boldsymbol{i}}$ & $\boldsymbol{N}_{\boldsymbol{i}}$ & $\boldsymbol{F}$ & $\boldsymbol{b}_{\boldsymbol{i}}$ \\
\hline 1 & 1.000 & $\mathrm{NA}$ & 1 & 1.000 & $\mathrm{NA}$ \\
2 & 0.423 & -1.241 & 2 & 0.378 & -1.404 \\
3 & 0.288 & -1.132 & 3 & 0.124 & -1.897 \\
4 & 0.154 & -1.350 & 4 & 0.060 & -2.031 \\
5 & 0.110 & -1.371 & 5 & 0.051 & -1.853 \\
6 & 0.089 & -1.351 & 6 & 0.028 & -2.003 \\
17 & 0.044 & -1.101 & 8 & 0.023 & -1.813 \\
29 & 0.022 & -1.133 & 12 & 0.018 & -1.607 \\
& & & 13 & 0.014 & -1.669 \\
& & & 50 & 0.009 & -1.271 \\
& & & 58 & 0.005 & -1.325 \\
\hline
\end{tabular}

As shown in Table 4 , it is easy to establish a normal distribution for the slope $b_{i}$ with specified or $96 \%$ reliability. The normal distribution analysis on slope $b_{i}$ based on Equation (2), and the predictions with mean value and with upper and lower bounds based on Equation (3), are shown in Figures 6 and 7 , together with the corresponding best-fitted curves.
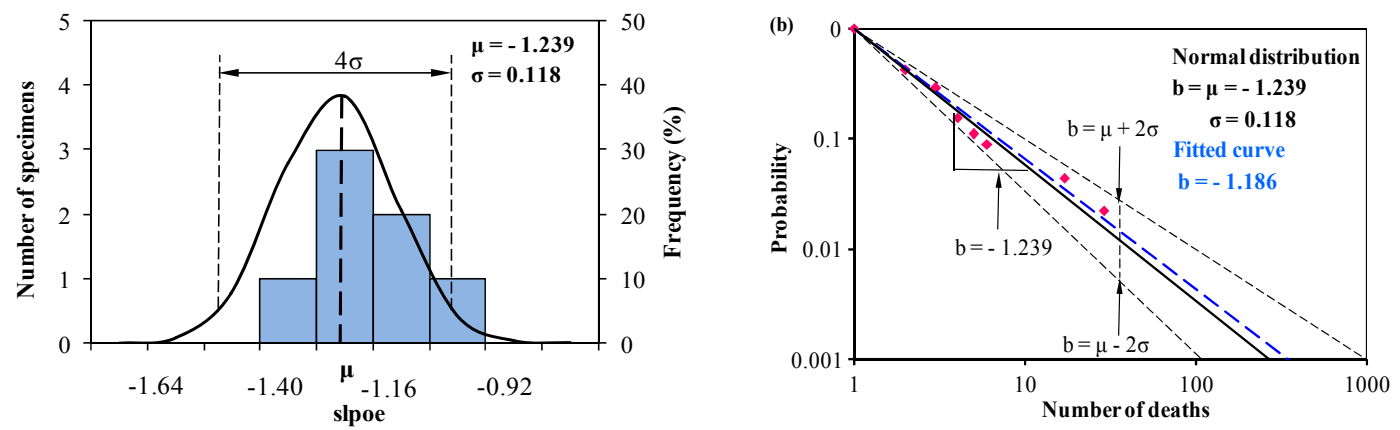

Figure 6. (a) Normal distribution analysis of the slope $b_{i}$ determining the relation between the accumulated frequency and number of deaths, and (b) predictions from Equation (1) and Equation (3) based on the normal distribution analysis of $b_{i}$ in (a) together with the statistical data from 2000 to 2008 in China digitized from Yang et al. [12].

Figure 6a shows that $b_{i}$ is normally distributed with the mean value $\mu=-1.239$ and the standard deviation $\sigma=0.118$. The fitted-curve $(b=-1.186)$ plotted by using the digitized data is slightly different from the original result in the literature. This small error may come from digitization of the experimental data. However, the digitized error is acceptable. In Figure $6 b$, different from the fitted curve, the mean value curve is close to the first few data points with less than or equal to 6 deaths, which is more representative.

Figure 7a shows that $b_{i}$ is normally distributed with the mean value $\mu=-1.687$ and the standard deviation $\sigma=0.278$. In Figure $7 \mathrm{~b}$, the mean value curve is lower than the best-fitted curve because accidents are within severe fluctuation (i.e., 40 and 58 deaths in accidents) in this sample. This indicates the mean value curve is better than the fitted curve. 

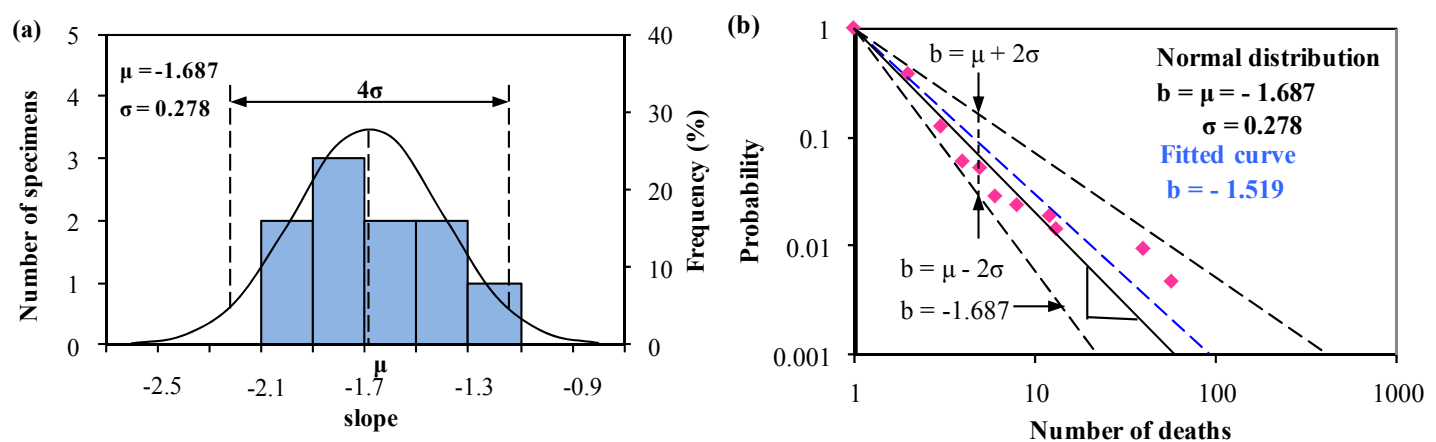

Figure 7. (a) Normal distribution analysis of the slope bi determining the relation between the accumulated frequency and number of deaths, and (b) predictions from Equation (1) and Equation (3) based on the normal distribution analysis of $b_{i}$ in (a) together with the statistical data from 2013 to 2017 in China.

Figures 6 and 7 show that from 2000-2008, the slope of the mean value curve $(\mu=-1.239)$ is much higher than that in 2013-2017 ( $\mu=-1.687)$. Moreover, the slope of the predicted upper and lower bounds with $96 \%$ reliability ranges from -1.475 to -1.003 in $2000-2008$, and from -2.232 to -1.142 in 2013-2017. This indicates China has made great improvement in decreasing the deaths of accident occurred in road hazardous material transportation.

\section{Discussion}

\subsection{Fatal Transportation Accidents by Road and Rail}

According to the statistical data of hazardous material transportation, accidents occurring on a railway are much less frequent than that on a road, while research shows that the consequence of an accident is likely to be more severe if the accident occurs on a railway rather than on a road [11]. The same conclusion was obtained through the analysis of the mean value curve- the slope is -0.77 for road accidents (Figure 1) and -0.75 for rail accidents (Figure 2). However, predictions on the upper and lower bounds with $96 \%$ reliability $( \pm 2 \sigma)$ show that the relative probability of the fatalities of road accidents ( 4.1 to 8.4 ) ranges larger than the rail accidents (4.3 to 7.5). This indicates that in some cases, the road accident-severity may be more severe than rail because the consequences of an accident are determined by possible causes, for example, impact failure, mechanical failure, human factor and external conditions, and by emergency responses. Besides, railway hazmat transportation has a fixed route system and each train involves multiple cars with hazardous material. Once a hazmat train derailed, multiple tank cars may release [22]. This usually leads to severe consequences in a particular scope. Research on the train derailment severity of derailed cars has been carried out in recent years [23-26].

\subsection{The Impact of the Development Levels}

In Group 1 and Group 2, the slopes of the mean value curves are approximately -1.1 (Figures 3-5), which is in agreement with the result in Oggero et al. [11] and Carol et al. [27]. Subtle differences can be described by using the upper and lower boundaries with $96 \%$ reliability. In Group 1, the relative probability ranges from 5.8 to 29.1, while in Group 2 this value ranges from 5.4 to 26.7. This indicates that the consequences of an accident are likely to be identical or more severe if the accident occurs in the European Union than in the countries of Group 1. In Group 3, the relative probability of upper and lower limits ranges from 1.4 to 5.1, which is far less than the first two groups. This result is identical to the hypothesis of Law et al. (2011) [28]. Considering the levels of economic development, it is found that the developing countries in Group 3 are at the early stage of industrialization and pay little 
attention on safety programmes. In developed countries, the severity of fatal accidents declines as the per capita income increases and the improvement in safety management.

\subsection{The Evolution of Accident Severity}

Combining the five stages in safety production and the development of the social economy [1,29], the severity of fatal accidents occurred in hazmat transportation will undergo five stages correspondingly. The five stages are as follows: Stage 1-the severity is relatively low with few transportation accidents in agricultural economy; Stage 2-the severity increases as the number of accidents increase in early industrialization; Stage 3-the severity reaches a general trend with fluctuations in middle industrialization; Stage 4-a general decline of accident severity in advanced industrialization is seen; Stage 5-a stabilized period for accident severity in the information society is seen.

By comparing the slope of the mean value curve in Figure $6 \mathrm{~b}$ and in Figure $7 \mathrm{~b}$, it shows that the consequences of an accident are likely to be slightly less severe if the accident occurred in 2013-2017 rather than in 2000-2008. This indicates that in China the severity of fatal accidents in hazardous material transportation has decreased as a whole. Considering the above result and the reduction of safety accidents [30-32], China is at Stage 4 in the evolution of the accident severity in hazardous material transportation. This achievement may be attributed to the development of social economy and the implementation of national safety programmes, such as the 5-year plans for safety production.

\section{Conclusions}

For the fatalities analysis of accidents, the common practice is to fit the average results (i.e., fitting an $f-N$ curve) regardless how large the scatters in statistical results are. In this study, by combination of normal distribution and the $f-N$ curve, a simple and reliable methodology is proposed for accident data analysis. On the basis of this theory, we presented the fatal accidents by groups of transport modes (i.e., road and rail), countries, and periods, respectively. It is evident that the mean value curves are almost identical or even better than the linear-fitted curves, but the predicted upper and lower limits with $96 \%$ reliability covering nearly all the statistical data are beyond the scope of common curve fitting. With the development of social economy and safety requirements, the evolution of accident-severity undergoes five stages. Usually in developed countries the severity of fatalities is less severe than that in developing countries, because infrastructures and safety measures during the transportation of hazardous material are not effective in developing countries.

In principle, the methodology presented in this study on the fatalities analysis can be used to evaluate safety policies and propose countermeasures for the transportation of hazardous material. This will make relevant study more objective than the common practice of curve fitting as routinely done.

Author Contributions: Statistical analysis, C. R.; Writing-Original Draft Preparation, C. R.; Projection Administration, Q. W., S. Z.; Methodology, C. Z.; Writing-Review \& Editing, C.Z.

Funding: This work was funded by the National Natural Science Foundation of China (11672048 \& 51405029), Shaanxi Province (2017KJXX-11 \& 2016JQ5020) and Chang'an University (310825153510).

Conflicts of Interest: The authors declare no conflict of interest.

\section{References}

1. Duan, W.L.; Chen, G.H.; Ye, Q.; Chen, Q.G. The situation of hazardous chemical accidents in China between 2000 and 2006. J. Hazard. Mater. 2011, 186, 1489-1494. [CrossRef] [PubMed]

2. Shen, X.Y.; Yan, Y.; Li, X.N.; Xie, C.J.; Wang, L.H. Analysis on tank truck accidents involved in road hazardous materials transportation in China. Traffic Inj. Prev. 2014, 15, 762-768. [CrossRef] [PubMed]

3. Montiel, H.; Vílchez, J.A.; Arnaldos, J.; Casa, J. Historical analysis of accidents in the transportation of natural gas. J. Hazard. Mater. 1996, 51, 77-92. [CrossRef] 
4. Ellis, J. Analysis of accidents and incidents occurring during transport of packaged dangerous goods by sea. Saf. Sci. 2011, 49, 1231-1237. [CrossRef]

5. Zhang, H.D.; Zheng, X.P. Characteristics of hazardous chemical accidents in China: A statistical investigation. J. Loss Prev. Process Ind. 2012, 25, 686-693. [CrossRef]

6. Abdolhamidzadeh, B.; Abbasi, T.; Rashtchian, A.; Abbasi, S.A. Domino effect in process-industry accidents: An inventory of past events and identification of some patterns. J. Loss Prev. Process Ind. 2011, 24, 575-593. [CrossRef]

7. Brüde, U. What is happening to the number of fatalities in road accidents? A model for forecasts and continuous monitoring of development up to the year 2000. Accid. Anal. Prev. 1995, 27, 405-410. [CrossRef]

8. Savolainen, P.T.; Mannering, F.L.; Lord, D.; Quddus, M.A. The statistical analysis of highway crash-injury severities: A review and assessment of methodological alternatives. Accid. Anal. Prev. 2011, 43, 1666-1676. [CrossRef] [PubMed]

9. Milton, J.C.; Shankar, V.N.; Mannering, F.L. Highway accident severities and the mixed logit model: An exploratory empirical analysis. Accid. Anal. Prev. 2008, 40, 260-266. [CrossRef] [PubMed]

10. Blincoe, L.; Seay, A.; Zaloshnja, E.; Miller, T.; Romano, E.; Luchter, S.; Spicer, R. The Economic Impact of Motor Vehicle Crashes; NHTSA Technical Report; NHTSA: Washington, DC, USA, 2002.

11. Oggero, A.; Darbra, R.M.; Muñoz, M.; Planas, E.; Casal, J. A survey of accidents occurring during the transport of hazardous substances by road and rail. J. Hazard. Mater. A 2006, 133, 1-7. [CrossRef] [PubMed]

12. Yang, J.; Li, F.Y.; Zhou, J.B.; Zhang, L.; Huang, L.; Bi, J. A survey on hazardous materials accidents during road transport in China from 2000 to 2008. J. Hazard. Mater. 2010, 184, 647-653. [CrossRef] [PubMed]

13. Planas-Cuchi, E.; Montiel, H.; Casal, J. A survey of the origin, type and consequences of fire accidents in process plants and in the transportation of hazardous materials. Process Saf. Environ. 1997, 75, 3-8. [CrossRef]

14. Vílchez, J.A.; Sevilla, S.; Montiel, H.; Casal, J. Historical analysis of accidents in chemical plants and in the transportation of hazardous materials. J. Loss Prev. Process Ind. 1995, 8, 87-89. [CrossRef]

15. Rømer, H.; Haastrup, P.; Petersen, H.J.S. Accidents during marine transport of dangerous goods. Distribution of fatalities. J. Loss Prev. Process Ind. 1995, 8, 29-34. [CrossRef]

16. Hemmatian, B.; Abdolhamidzadeh, B.; Darbra, R.M.; Casal, J. The significance of domino effect in chemical accidents. J. Loss Prev. Process Ind. 2014, 29, 30-38. [CrossRef]

17. Darbra, R.M.; Palacios, A.; Casal, J. Domino effect in chemical accidents: Main features and accident sequences. J. Hazard. Mater. 2010, 183, 565-573. [CrossRef] [PubMed]

18. Zhang, C.G.; Hu, X.Z.; Sercombe, T.; Li, Q.B.; Wu, Z.M. Prediction of ceramic fracture with normal distribution pertinent to grain size. Acta Mater. 2018, 145, 41-48. [CrossRef]

19. Sedić, A.; Packović, D.; Firak, M. A methodology for normal distribution-based statistical characterization of long-term insolation by means of historical data. Sol. Energy 2015, 122, 440-454. [CrossRef]

20. Hauer, E. The frequency-severity indeterminacy. Accid. Anal. Prev. 2006, 38, 78-83. [CrossRef] [PubMed]

21. National Highway Traffic Safety Administration. Traffic Safety Facts: Motorcycles; DOT HS 811 159; National Highway Traffic Safety Administration: Washington, DC, USA, 2009.

22. Liu, X.; Saat, M.R.; Barkan, C.P.L. Probability analysis of multiple-tank-car release incidents in railway hazardous materials transportation. J. Hazard. Mater. 2014, 276, 442-451. [CrossRef] [PubMed]

23. Saccomanno, E.F.; EI-Hage, S.M. Minimizing derailments of railcars carrying dangerous commodities through effective marshaling strategies. Transp. Res. Rec. 1989, 1245, 34-51.

24. Saccomanno, E.F.; EI-Hage, S.M. Estabilishing derailment profile by position for corridor shipments of dangerous goods. Can. J. Civ. Eng. 1991, 18, 67-75. [CrossRef]

25. Barkan, C.P.L.; Dick, C.T.; Anderson, R.T. Railroad derailment factors affecting hazardous materials transportation risk. Transp. Res. Rec. 2003, 1825, 64-74. [CrossRef]

26. Liu, X.; Saat, M.R.; Barkan, C.P.L. Analysis of causes of major train derailment and their effect on accident rates. Transp. Res. Rec. 2012, 2289, 154-163. [CrossRef]

27. Carol, S.; Vílchez, J.A.; Casal, J. Study of the severity of industrial accidents with hazardous substances by historical analysis. J. Loss Prev. Process Ind. 2002, 15, 517-524. [CrossRef]

28. Law, T.H.; Noland, R.B.; Evans, A.W. The sources of Kuznets relationship between road fatalities and economic growth. J. Transp. Geogr. 2011, 19, 355-365. [CrossRef]

29. Zheng, W.X. Report on Occupational Safety vs Economic and Social Development; China Coal Industry Publishing House: Beijing, China, 2006. 
30. State Council of China. The 12th Five-Year Planning of Safety Production; State Council of China: Beijing, China, 2017.

31. State Council of China. The 11th Five-Year Planning of Safety Production; State Council of China: Beijing, China, 2011.

32. State Council of China. The 10th Five-Year Planning of Safety Production; State Council of China: Beijing, China, 2008. 